\title{
Stair safety: bottom of flight illusion
}

\author{
Daniel Johnson \\ Daniel A. Johnson, Inc., 6221 Swayne Drive NE, Olympia, WA, U.S.A.
}

\begin{abstract}
Falls near the bottom of a flight of stairs have resulted from an illusion that the person was stepping off onto the bottom landing when the person was still two treads or more above the landing. The illusion is caused by poor lighting and design defects built into the stairway. The poor lighting may be attributed to a building code that allows inadequate lighting near the bottom of external stairs in private residences. The design defect of truncating handrails before they reach the bottom tread may be due to confusion between "guards" and "handrails" and this confusion also appears to be promulgated by building code.
\end{abstract}

Keywords: Stairs, handrails, guards, falls, lighting, design

\section{Introduction}

Falls during descent near the bottom of a stairway occur when a person mistakenly thinks the nextto-bottom tread is actually the bottom landing. This "Bottom of Flight Illusion" is due to a lack of lighting at the bottom landing, or by design defects consciously built into the stairway.

There are several visual cues that inform a stair user that one is about to step off onto a bottom landing:

The landing itself is visible and distinguishable from the treads leading down to it;

The handrail(s) extends at least to the bottom tread, and perhaps beyond; and

There is sufficient illumination.

When these conditions exist there should be no bottom of flight illusion.

Some building codes allow stairs in private residences to be built to lower safety standards than those in the public sector. This disparity in safety between private and public domains has been the topic of recent extensive discussions where Pauls [9] has pointed out that more stair injuries are happening in private residences than on public stairs. The injury rate appears to be decreasing on public stairs while, at the same time, increasing on private stairs. One likely cause has been attributed to the "Top of Flight Flaw". This occurs when the first tread below the top landing has a larger run (or going) than subsequent treads, inducing stair users to place their feet too far forward on the second or third runs. This can result in a misstep and potentially fatal fall $[7,8]$. But, to date, the bottom of flight illusion has received scant attention.

Building code may actually contribute to the bottom of flight illusion. One code-induced contribution would be the allowance of poor lighting near the bottom of the flight in private residences. Another codeinduced contribution could be the confusion between "guards" and "handrails" that has resulted in builders truncating a handrail before the bottom tread.

\section{Poor lighting}

Falls on stairs can occur when people are unable to adequately see where to place their feet. Carson et al. report that, where the lighting level was 2 foot candles or lower, incidents on stairs were twice as common than where the lighting was 8 foot candles or more [2].

Hamel et al. [4] found that under good lighting (i.e., $28 \mathrm{fc}$ ) both young adults (average age of 24) and old adults (average age of 74) could descend stairs without their shoes grazing the intermediate treads. But under poor lighting ( 3 lux, or $0.28 \mathrm{fc}$ ) the younger adults adapted by lifting their shoes higher, whe- 
reas the older adults did not so adapt. As a result the older adults had missteps when their feet grazed the intermediate steps.

If the lighting does not adequately illuminate the lower section of a stairway a user may believe the foot is being placed onto the landing when it is actually being placed onto a tread above the landing. This can lead to the foot being placed too far forward and then pivoting over the nosing of the bottom tread. In addition to a serious trauma to the foot and ankle, a fall resulting in serious injuries to the upper extremities and head can occur.

The illusion can also induce the stair user, stepping down onto the bottom tread, to believe there is another tread before the landing is reached. When the foot contacts the bottom landing it can cause the person to stumble forward, and perhaps fall.

Poor illumination near the bottom of stairs has resulted in serious falls but is allowed by the International Residential Code [6]. While treads and landings throughout the stairway in a public setting must be illuminated with an intensity of 1 foot candle [5], for one- and two-family dwellings a luminaire is required only in the "immediate vicinity of the top landing" of an exterior stairway [6]. According to this Code the intermediate treads of exterior stairways, as well as the bottom treads and landing, need not receive any specific amount of illumination, e.g. 1 foot candle.

\subsection{Poor design Case 1}

An example of the design of the external staircase that was poorly illuminated and which was implicated in a fall when a woman was descending the stairs is seen in Figure 1. She had her hand on the left handrail. The handrail on the right was of little use since it was too close (13 mm, 0.5 in) to the wall for her hand to follow. When she was near the bottom of the "pitch black" stairway she stepped off to her left onto what she thought was a lower landing (see Figure 2.) She fell and fractured an ankle.

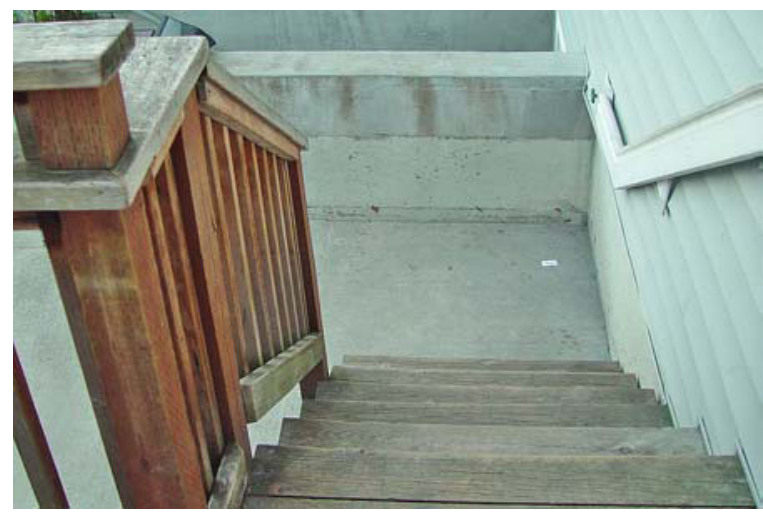

Fig. 1. A woman was descending this darkened stairway and stepped off to her left onto what she thought was the bottom landing.

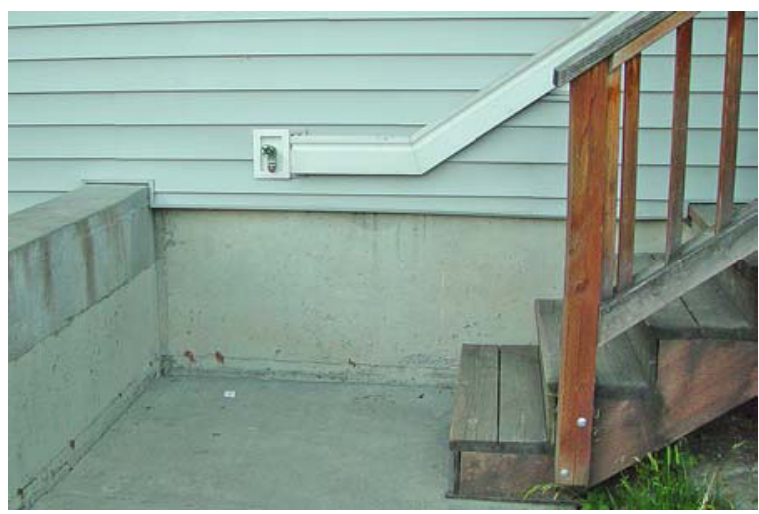

Fig. 2. She was not aware the handrail on her left ended before the bottom landing.

\subsection{Poor design Case 2}

In this instance a 78-year-old woman had walked up the stairs of a model home that was on permanent display. When she was descending the lighting was adequate since there were several nearby windows and the sun was high in the sky. 


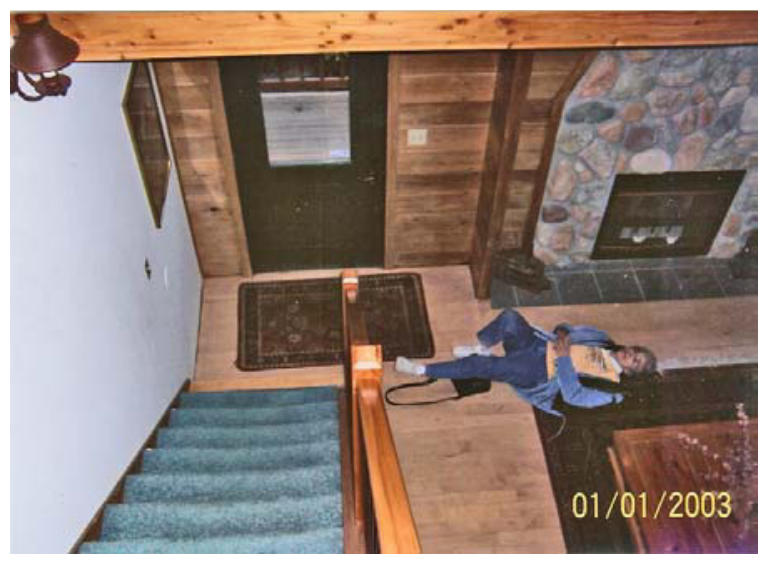

Fig. 3. A relative took this photograph soon after the woman fell. The bottom tread resembles the bottom landing. (Photo used with permission. Date stamp is incorrect.)

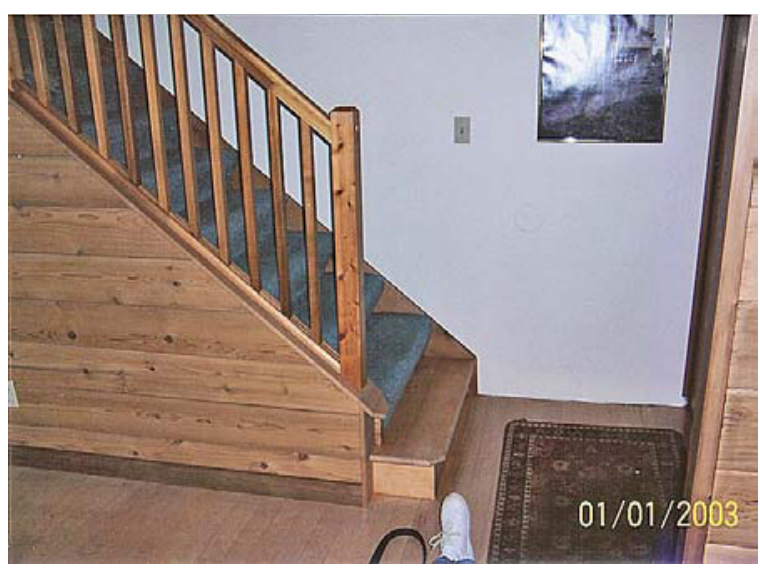

Fig. 4. The bottom tread, difficult to discriminate from the landing when a person is on the stairs, is obvious in profile. (Photo used with permission. Date stamp is incorrect.)

As can be seen in Figure 3, from above the bottom tread was of the same appearance as the bottom landing. All the other treads were carpeted and the handrail stopped two treads above the bottom landing. These cues apparently led her to believe that when she stepped onto the bottom tread she was stepping onto the bottom landing (see Figure 4). As she fell she grabbed for the handrail but it truncated a step above the bottom tread. She fractured her left proximal femur.

\subsection{Poor design Case 3}

In a similar incident a 51-year-old woman was descending a stairway she had never been on before. The lighting was subdued. Figure 5 shows what was visible to her as she approached the bottom landing.

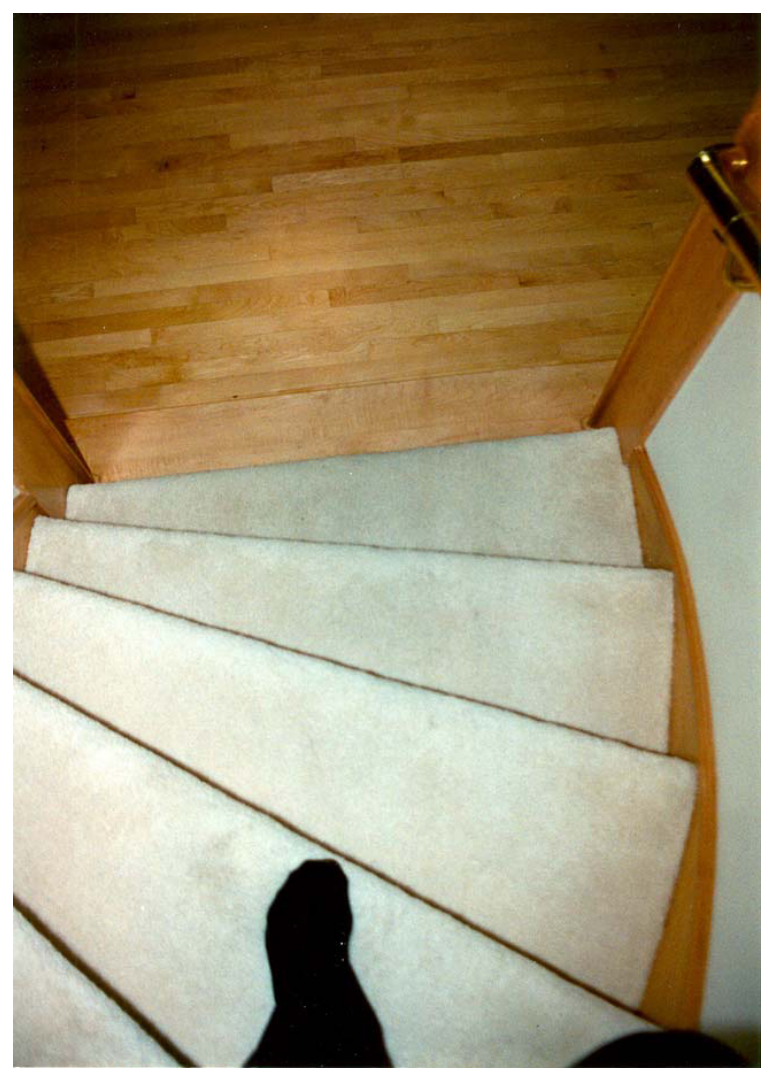

Fig. 5. As seen from above the stairs and the lower landing are quite apparent. The bottom tread is not conspicuous. (The photographer's foot, however, is.)

When she placed her foot on the wooden tread it pivoted and slid over the nosing. When her foot impacted the lower landing it resulted in a Lizfranc fracture of her foot. Again, in profile, the bottom tread is obvious (see Figure 6). Further, the hard-tograsp handrail did not extend to the bottom nosing.

Why builders would install a handrail that stopped short of the bottom tread was puzzling until a remark by the contractor in Case 1 was considered. 


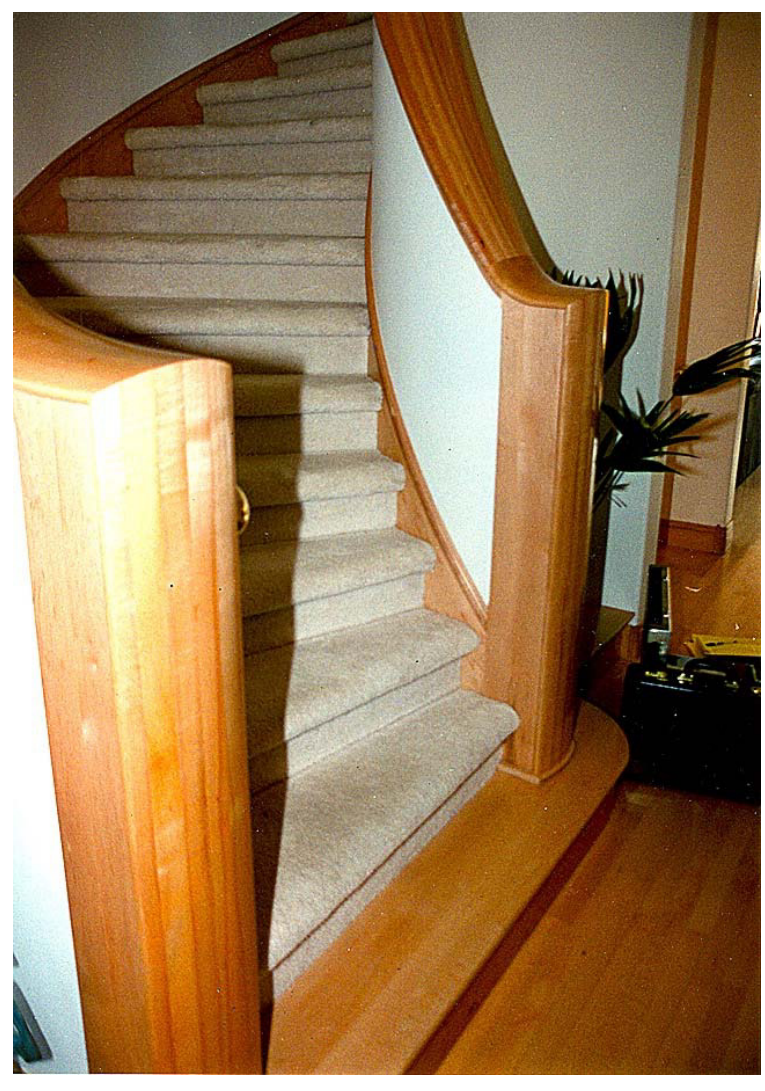

Fig. 6. In profile the bottom tread is obvious. Notice that the handrails stop short of the bottom nosing.

\section{Confusion between guard and handrail}

The contractor in Case 1 believed the code, which states no guard is needed if the open side of a stairway is $762 \mathrm{~mm}$ (30 in) or less above a floor, also means that no handrail is needed in that situation. That is an incorrect conclusion, but, as described below, it is an understandable mistake. It appears the builder had confused handrails for guards.

"Guards" and "handrails" have quite separate functions. Guards are to prevent people from falling from open-sided walking surfaces located more than $762 \mathrm{~mm}$ (30 in) above the floor or grade [5]. On the other hand, handrails on stairways or ramps are provided for people to grasp to prevent a fall. Other functions of handrails are described in [1].

There is a code requirement that handrails extend at least the full length of the stairway and, in some instances, must extend $305 \mathrm{~mm}$ (12 in) beyond the bottom and top risers [5]. However, there is also a code for residences that no guard is needed if the drop off is less than $762 \mathrm{~mm}$ (30 in) [6].
The International Building Code (IBC) contributes to the confusion when it states that, for certain residences, "where the top of the guard also serves as a handrail on the open sides of stairs, the top of the guard shall not be less than $864 \mathrm{~mm}$ (34 in) and not more than $965 \mathrm{~mm}$ (38 in) measured vertically from a line connecting the leading edges of the treads" [5].

Confusion is caused because the allowable 864 $\mathrm{mm}$ to $965 \mathrm{~mm}$ (34 to $38 \mathrm{in}$ ) range for the guard is the same as the height range for handrails. Unfortunately, in addition to confusing the guard - handrail distinction, it also results in guards that are much too low.

Guards are to be $1067 \mathrm{~mm}$ (42 in) above the walking surface in order to prevent a $97.5^{\text {th }}$ percentile male from falling over the guard [3]. These researchers determined that the $1067 \mathrm{~mm}$ (42 in) height is slightly above the calculated $1046 \mathrm{~mm}$ (41.2 in) high "centroid", the center of gravity (CG) of the $97.5^{\text {th }}$ percentile male. Should a person of that height, or shorter, fall against or inadvertently walk into the guard, most person's CG would be below $1067 \mathrm{~mm}$ (42 in), and the guard would likely prevent the person from toppling over the rail.

The code-allowed $203 \mathrm{~mm} \quad(34 \quad$ in $)$ guard/handrail would not prevent many from accidently falling over the guard/handrail. Based on figures available in [3] the calculated $50^{\text {th }}$ percentile centroids of males and females are $965 \mathrm{~mm}$ and 889 $\mathrm{mm}$ (38 in and 35 in) respectively. Thus, a codeallowed guard/handrail, with a height of only 864 $\mathrm{mm}$ (34 in), would not provide adequate fall protection for more than half of the population.

It is not clear why low guard/handrails in private residences are allowed by the IBC but simultaneously disallowed in public facilities. It appears likely that these practices are contributing to the increase in falls in residences pointed out by Pauls [9]. It may be that lawsuits against homeowners are much less likely than suits against the owners and builders of public facilities.

The two egregious safety and code violations, poor illumination and truncated handrails on stairs in private residences, produce visual cues that have resulted in injurious falls due to the bottom of flight illusion. In each case it appears that the code contributed to an unsafe condition. This has implications for those writing codes, as well as for building inspectors who should perform the task of insuring a home is fit for safe occupation before issuing a permit. 


\section{References}

[1] Archea, J., Collins, B., \& Stahl, F. (1979). Guidelines for stair safety. NBS building science series 120. Washington, DC: National Bureau of Standards.

[2] Carson, D.H., Archea, J.C., Margulis, S.T. \& Carson, F.E. (1978). Safety on stairs. NBS Building Science Series 108. Washington, DC: National Bureau of Standards.

[3] Fattal, S.G., Cattaneo, L.E., Turner, G.E., \& Robinson, S.N (1976). Personnel guardrails for the prevention of occupational accidents, NBSIR 76-1132. Washington, DC: National Bureau of Standards.

[4] Hamel, K.A., Okita, N., Higginson, J.S. \& Cavanagh, P.R. (2005). Foot clearance during stair descent: effects of age and illumination. Gait and Posture, 21, 135 - 140.

[5] IBC International Building Code (2012). Falls Church, VA: International Code Council.
[6] IRC International Residential Code for One-and Two-Family Dwellings (2012). Falls Church, VA: International Code Council.

[7] Johnson, D.A. (2009) Improper construction results in dangerous stairs: Large top runs produce fall hazard. Proceedings of the 53rd Annual Meeting of the Human Factors and Ergonomics Society. Santa Monica, CA: Human Factors and Ergonomics Society.

[8] Johnson, D.A. \& Pauls, J. (2010). Systemic stair step geometry defects, increased injuries, and public health plus regulatory responses. In Anderson, M. (Ed.) Contemporary Ergonomics and Human Factors. Boca Raton, FL: CRC Press.

[9] Pauls, J. (2011). Injurious Falls on Stairways: Background for international conference in June 2011. Proceedings of International Conference on Slips, Trips and Falls, STF2011, Health and Safety Laboratory, UK. 